\title{
Pregnancy Mask: Melasma
}

\author{
Merve Meryem Kalaycı (1)
}

Melasma is a skin disease that is clinically characterized by the development of gray-brown macules. It is derived from the Greek word "melas", and the word meaning is black. It is also called "chloasma gravidarum", that is, the pregnancy mask. ${ }^{[1]}$ Chloasma is derived from the word chloazein from Greek and means green. ${ }^{[2]}$ Melasma and chloasma are used synonymously in the literature. However, since the resulting pigmentation is gray-brown, the term melasma is more preferred. ${ }^{[3]}$

\section{Epidemiology-Etiology}

Melasma occurs in all races and ethnicities, but it has been demonstrated that it is more common in individuals and women with Fitzpatrick IV-VI skin types, including those living in intensive ultraviolet irradiated areas including indiviuals of Hispanic, Asian, and African descent. ${ }^{[4-8]}$ Fitzpatrick skin classification is based on a person's response to sun exposure. I-III types are known as light skin, while IV-VI types are accepted as dark skin. ${ }^{[9,10]}$

Skin diseases are observed equally frequently in women who are pregnant and not pregnant. While $90 \%$ of chloasma cases are women, pregnant women constitute $50 \%-70 \%$ of this rate. ${ }^{[11,12]}$ For this reason, it is the most common cosmetic problem related to pregnancy. Male patients constitute $<20 \%$ of cases of melasma. ${ }^{[13,14]}$

İstanbul Gelişim University School of Nursing, Istanbul, Turkey

Correspondence: Merve Meryem Kalaycı. İstanbul Gelişim Üniversitesi Hemşirelik Yüksekokulu, 34310 Avcılar, İstanbul, Türkiye.

Cite this article as: Kalaycı MM. Pregnancy Mask: Melasma. JEB Med Sci 2020;1(2):65-67.

doi: $10.5606 /$ jebms.2020.75614

Received : August 24, 2020

Accepted : September 05, 2020

Published online : November 09, 2020

(C2020 Journal of Experimental and Basic Medical Sciences. All rights reserved.

\begin{abstract}
Melasma is the gray-brown hyperpigmentation of the skin. It is also known as the pregnancy mask. Skin diseases are observed equally frequently in women who are pregnant and not pregnant. While $90 \%$ of melasma cases are women, $50 \%$ to $70 \%$ of this rate is pregnant women. For this reason, it is the most common cosmetic problem related to pregnancy. Its etiology is still unknown. There are studies that include the main factors causing its occurrence; exposure to UV radiation, pregnancy, genetic factors, hormonal therapies and cosmetic product use. The most effective way to be protected from melasma is to avoid excessive exposure to the sun in order to prevent its formation during pregnancy.

Keywords: Hormone, melasma, pregnant, sun.
\end{abstract}

Melasma etiology is still unknown. However, many factors are involved in the development of the disease, etiologically and pathologically. Etiological factors invloved in the pathogenesis of melasma include exposure to UV radiation, pregnancy, genetic factors, hormonal treatments and cosmetic products. ${ }^{[15]}$ In a prospective study of 197 patients in Tunisia in 2010, aggravating factors of melasma were evaluated and sun exposure was accepted as the main aggravating factor. ${ }^{[16]}$ UV-A and UV-B are the main radiation sources causing melanogenesis. The role of infrared radiation and visible light, which has a significantly low melanogenic potential, in the development and maintenance of melasma, is still uncertain. ${ }^{[17,18]}$ The use of cosmetics and the use of certain medications, such as anticonvulsants and other photosensitizers, have also been shown as risk factors for melasma. ${ }^{[19,20]}$ Similarly, a wide variety of chemicals such as arsenic, iron, copper, bismuth, silver, gold, and drugs such as antimalarials, tetracyclines, anticonvulsants, amiodarone, sulfonylureas can induce hyperpigmentation of the skin and stimulate melanogenesis by accumulation in the surface layers. ${ }^{[21,22]}$ 


\section{CAUSATION FACTORS OF MELASMA IN PREGNANCY}

Immunological, metabolic, endocrine and vascular changes that occur during pregnancy initiate a number of physiological and pathological processes in the skin and its associated regions. Physiological skin changes during pregnancy are most likely due to hormonal changes associated with pregnancy. Serious physiological skin changes can sometimes be pathologically acceptable. The cause of melasma is the change in pigments during pregnancy. ${ }^{[23,24]}$

It is believed that one of the main reasons why melasma is seen more intensely during pregnancy is due to hormonal changes. Melasma is observed in the form of gray-brown spots on the face during the second trimester of pregnancy. Melasma with regular hyperpigmentation is clinically divided into three types: centrofacial (63\%), malar (21\%) and mandibular $(16 \%)^{[3]}$

It was found that increased melasma during pregnancy also had a positive relationship with oral contraceptives. It has been demonstrated that $10-20 \%$ of women using oral contraceptives for 1-3 years may develop melasma. ${ }^{[7,25]}$ While the role of progesterone as a triggering or protective factor is still uncertain, it has been found that estrogen may play a role in the pathogenesis of melasma in the results of various in vitro studies. ${ }^{[26]}$ In another study conducted in 2007, increased vascularity and epidermal vascular endothelial growth factor were found to be one of the most important findings in melasma and showed that the number of dermal vessels correlated positively with pigmentation on the skin affected by melasma. ${ }^{[27]}$ After birth, melasma regresses, but never disappears, and recurrence and exacerbation of melasma is common in subsequent pregnancies. ${ }^{[7]}$

\section{PROTECTION AND TREATMENT}

Melasma pigmentation generally improves in winter and worsens in summer. ${ }^{[28]}$ The most effective way to prevent melasma formation is to avoid sun exposure during pregnancy. ${ }^{[29]}$ The use of sunscreen with a high protection value reduces the severity of the disease by $50 \%$ and reduces its incidence during pregnancy by more than $90 \% \cdot{ }^{[30,31]}$ During a 12-month clinical trial, the role of broad-spectrum sun protection in the prevention and treatment of chloasma in pregnant women was evaluated. The results indicated that only five new cases of melasma, a $2.7 \%$ incidence and lower than $53 \%$ previously observed during pregnancy was recorded. ${ }^{[30]}$
In order to reach the correct diagnosis, a detailed medical history, detailed clinical examination of the skin, dermoscopy and histopathology must be taken and recorded. ${ }^{[13]}$ Commonly used agents for treating melasma include hydroquinone, azelaic acid, kojic acid, glycolic acid, salicylic acid and tretinoin. Of these processes, hydroquinone is the gold standard..$^{[4,7,27]}$ The pregnancy category of drugs frequently applied for hyperpigmentation treatment such as hydroquinone and retinoic acid is C. ${ }^{[32]}$ Multiple studies show that combination formulations offer the best results. These triple combination formulas usually contain different concentrations of hydroquinone, a retinoid, and a corticosteroid. The commonly used treatments mentioned above are often associated with universal recurrences. Second-line treatments, such as chemical peel and lasers, are effective in some patients, but these approaches can be associated with acute or long-term complications, especially in people with dark skin types. The search for effective treatments for melasma is still ongoing. ${ }^{[33]}$

\section{Declaration of conflicting interests}

The authors declared no conflicts of interest with respect to the authorship and/or publication of this article.

\section{Funding}

The authors received no financial support for the research and/or authorship of this article.

\section{REFERENCES}

1. Kasp-Grochowska E, Beck J, Holmes RC, Black MM, Timlin $D$. The role of circulating immune complexes in the aetiology of polymorphic eruption of pregnancy. Arch Dermatol Res 1984;276:71-3.

2. Bolanca I, Bolanca Z, Kuna K, Vuković A, Tuckar N, Herman R, et al. Chloasma--the mask of pregnancy. Coll Antropol 2008;32 Suppl 2:139-41.

3. Sehgal VN, Verma P, Srivastava G, Aggarwal AK, Verma S. Melasma: treatment strategy. J Cosmet Laser Ther 2011;13:265-79.

4. Halder RM, Grimes PE, McLaurin Cl, Kress MA, Kenney JA Jr. Incidence of common dermatoses in a predominantly black dermatologic practice. Cutis 1983;32:388-90.

5. Kang HY. Melasma and aspects of pigmentary disorders in Asians. Ann Dermatol Venereol 2012;139 Suppl 3:S92-5.

6. Kim EH, Kim YC, Lee ES, Kang HY. The vascular characteristics of melasma. J Dermatol Sci 2007;46:111-6.

7. Moin A, Jabery Z, Fallah N. Prevalence and awareness of melasma during pregnancy. Int J Dermatol 2006;45:285-8.

8. Werlinger KD, Guevara IL, González CM, Rincón ET, Caetano R, Haley RW, et al. Prevalence of self-diagnosed melasma among premenopausal Latino women in Dallas and Fort Worth, Tex. Arch Dermatol 2007;143:424-5. 
9. Taylor SC. Skin of color: biology, structure, function, and implications for dermatologic disease. J Am Acad Dermatol 2002;46(2 Suppl Understanding):S41-62.

10. Czerkasij V. Skin of color: a basic outline of unique differences. Nurse Pract 2013;38:34-40.

11. Hughes BR. Melasma occurring in twin sisters. J Am Acad Dermatol 1987;17:841.

12. Cunningham FG, Leveno KJ, Bloom SL, Hauth JC, Gilstrap IIILC, Wenstrom KD. Teratology, Drugs, and other Medications. Williams Obstetrics; 2005.

13. Sarkar R, Ailawadi P, Garg S. Melasma in Men: A Review of Clinical, Etiological, and Management Issues. J Clin Aesthet Dermatol 2018;11:53-9.

14. Vachiramon $V$, Suchonwanit $P$, Thadanipon K. Melasma in men. J Cosmet Dermatol 2012;11:151-7.

15. Grimes PE. Melasma. Etiologic and therapeutic considerations. Arch Dermatol 1995;131:1453-7.

16. Guinot $C$, Cheffai $S$, Latreille J, Dhaoui MA, Youssef $S$, Jaber K, Nageotte O, Doss N. Aggravating factors for melasma: a prospective study in 197 Tunisian patients. J Eur Acad Dermatol Venereol 2010;24:1060-9.

17. Mahmoud $B H$, Ruvolo $E$, Hexsel $C L$, Liu $Y$, Owen $M R$, Kollias $\mathrm{N}$, et al. Impact of long-wavelength UVA and visible light on melanocompetent skin. J Invest Dermatol 2010;130:2092-7.

18. Mahmoud BH, Hexsel CL, Hamzavi IH, Lim HW. Effects of visible light on the skin. Photochem Photobiol 2008;84:450-62.

19. Pathak MA, Fitzpatrick TB, Kraus EW. Usefulness of retinoic acid in the treatment of melasma. J Am Acad Dermatol 1986;15:894-9.

20. Duarte I, Campos Lage AC. Frequency of dermatoses associated with cosmetics. Contact Dermatitis 2007;56:211-3.

21. Newcomer VD, Lindberg MC, Sternberg TH. A melanosis of the face ("chloasma"). Arch Dermatol 1961;83:284-99.

22. Sanchez NP, Pathak MA, Sato S, Fitzpatrick TB, Sanchez $\mathrm{JL}$, Mihm MC Jr. Melasma: a clinical, light microscopic, ultrastructural, and immunofluorescence study. J Am Acad Dermatol 1981;4:698-710.

23. Kroumpouzos G, Cohen LM. Dermatoses of pregnancy. J Am Acad Dermatol 2001;45:1-19.

24. StulbergDL,ClarkN,ToveyD.Commonhyperpigmentation disorders in adults: Part II. Melanoma, seborrheic keratoses, acanthosis nigricans, melasma, diabetic dermopathy, tinea versicolor, and postinflammatory hyperpigmentation. Am Fam Physician 2003;68:1963-8.

25. Cestari T, Arellano I, Hexsel D, Ortonne JP. Latin American Pigmentary Disorders Academy. Melasma in Latin America: options for therapy and treatment algorithm. J Eur Acad Dermatol Venereol 2009;23:760-72.

26. Kippenberger S, Loitsch S, Solano F, Bernd A, Kaufmann R. Quantification of tyrosinase, TRP-1, and Trp-2 transcripts in human melanocytes by reverse transcriptase-competitive multiplex PCR--regulation by steroid hormones. J Invest Dermatol 1998;110:364-7.

27. Kim EH, Kim YC, Lee ES, Kang HY. The vascular characteristics of melasma. J Dermatol Sci 2007;46:111-6.

28. Victor FC, Gelber J, Rao B. Melasma: a review. J Cutan Med Surg 2004;8:97-102.

29. Lakhdar H, Zouhair K, Khadir K, Essari A, Richard A, Seite $S$, et al. Evaluation of the effectiveness of a broadspectrum sunscreen in the prevention of chloasma in pregnant women. J Eur Acad Dermatol Venereol 2007;21:738-42.

30. Miot HA, Miot LD. Re: Topical $10 \%$ zinc sulfate solution for treatment of melasma. Dermatol Surg 2009;35:2050-1.

31. Nussbaum R, Benedetto AV. Cosmetic aspects of pregnancy. Clin Dermatol 2006;24:133-41.

32. Grimes PE, ljaz S, Nashawati R, Kwak D. New oral and topical approaches for the treatment of melasma. Int J Womens Dermatol 2018;5:30-6.

33. Benchikhi $H$, Razoki $H$, Lakhdar $H$. Sunscreens: use in pregnant women at Casablanca. Ann Dermatol Venereol 2002;129:387-90. 